\title{
Contra-relatos de vida e arte
}

\section{Ana María Vallejo de la Ossa}

Universidad de Antioquia Medelín, Colombia

anam.vallejo@udea.edu.co

orcid.org/0000-0002-0215-1465

Resumo | Por meio de uma abordagem do cotidiano e do trabalho criativo de quatro mulheres sul-americanas, vislumbramos possibilidades de formas de fazer e viver que ocorrem fora da lógica convencional da produção artística ligada à dinâmica do consumo. O cuidado - de si, dos outros, do ambiente, do vivo e das coisas - é importante dentro desses processos e é a dimensão comum que os relaciona. Graças a esses gestos de cuidado e arte, são gestadas poéticas que se opõem à grande história de medo e morte dominante hoje.

PALAVRAS-CHAVE: Mulheres. Capitalismo. Poética.

\section{Contra-relatos de vida y arte}

Resumen | Através de un acercamiento a la cotidianidad y al trabajo creativo de cuatro mujeres suramericanas, vislumbramos posibilidades de formas de hacer y de vivir que se dan por fuera de las lógicas convencionales de la producción artística ligada a las dinámicas de consumo. EI cuidado, de sí, de los otros, del entorno, de lo viviente y de las cosas, es importante dentro de estos procesos y es la dimensión común que los relaciona. Gracias a estos gestos de cuidado y arte, se gestan poéticas que se oponen al gran relato de miedo y muerte dominante hoy.

PALABRAS CLAVE: Mulheres. Capitalismo. Poética.

\section{Counter-stories of life and art}

Abstract | Through an approach to the daily life and creative work of four South American women, we glimpse possibilities of doing and living that occur outside the conventional logics of artistic production linked to consumption dynamics. Caring for oneself, others, the environment, the living and things, is important within these processes and is the common dimension that relates them. Thanks to these gestures of care and art, poetics are gestated to oppose the grand narratives of fear and death that dominate today.

KEYWORDS: Women. Capitalism. Poetics.

Enviado em: 25/10/2020

Aceito em: 14/12/2020

Publicado em: 18/12/2020 
Já se passaram vários meses desde que a pandemia foi declarada no mundo. As mais simples liberdades da vida diária são, agora, limitadas. Parece distante a possibilidade de romper com os novos hábitos que impõem o medo e o e confinamento, de cortar a rotina dos dias, de se deslocar, se encontrar ou viajar para entrar em contato com outros lugares e com outras pessoas. A morte, a doença e o seu contágio têm um verdadeiro protagonismo nas nossas vidas. Ligando ou não a televisão para assistir noticiários, fazendo parte ou não das mídias sociais, os rumores sobre a nova peste nos alcançam com frequência, invadem nossas conversas, instalam-se com maior ou menor força em nossos pensamentos. Em geral, é difícil ignorar a grande história da catástrofe, da perda e da angústia. Ao mesmo tempo, e talvez isso seja o mais significativo, a pandemia atuou como uma claríssima radiografia de uma catástrofe ainda maior, a da crescente desigualdade social em razão do modelo econômico capitalista. Na Colômbia, por exemplo, há uma grande população que foi confrontada com uma escolha trágica entre o contágio ou a fome. O governo não ofereceu uma renda básica, alegando o risco de desaceleração do crescimento econômico e empregando os slogans do culto ao progresso. Diante de tal crise geral, o pior seria, no entanto, render-se ao desânimo e jogar o jogo da impotência total. Por isso, com muita criatividade e gestos de resistência, outras visões de mundo são conquistadas aqui e ali, mesmo que temporariamente. A capacidade de invenção prova ser uma das armas mais eficazes contra o pessimismo paralisante próprio do que Isabelle Stengers e Philippe Pignarre chamariam de feitiço capitalista. Muitas comunidades e seus artistas sabem e praticam isso.

$\mathrm{Na}$ Colômbia, os meses de confinamento também foram marcados por um agravamento da violência já conhecida, mas mitigada durante os anos de negociações de paz entre o governo e as guerrilhas das FARC. Mais uma vez, o número de líderes sociais e ambientalistas, de defensores da vida em cidades, vilas, regiões remotas ou bairros marginalizados, é terrivelmente desolador e alarmante. Mais uma vez, os massacres são frequentes e mais uma vez a repressão é o instrumento de controle normalizado contra o protesto dos cidadãos.

Aqui, como em toda a América Latina, são tempos duros para as pessoas, para a natureza maltratada e, em meio a tudo isso, para os e as artistas que, a partir de sensibilidades particulares, estabelecem gestos em resposta a essa lógica da morte. Sabemos que infelizmente morrem línguas e tradições diariamente; da mesma forma, nesta época, em cada cidade e município do país, os teatros estão fechados, algum artista costura os lábios em protesto e muitos cinemas ou salas de exibição dormem em um sonho do qual podem não acordar.

Mas é importante dizer que mesmo no meio da pandemia e diante das medidas que impediram ou distorceram a vida de todas e todos nós e de uma maneira drástica os processos ou projetos de muitos coletivos artísticos, desencadeou-se ao mesmo tempo um fluxo sutil, mas visível, de contra-relatos de vida: narrativas, ações, gestos, obras, contrafábulas de esperança que se opõem à grande história do medo e às políticas de morte que os grandes poderes econômicos e políticos implantam, e não só por causa da pandemia, por todo o planeta. Entendemos tais práticas, modos de fazer, ou singulares laboratórios de criação, como formas possíveis de resistência em ressonância com a 
compreensão que Isabelle Stengers e Philippe Pignarre nos oferecem das formas dissidentes, diversas, não necessariamente enquadradas em partidos ou ideologias, mas que, desde cada cosmovisão, contribuem com as lutas anticapitalistas:

grupos em luta, como as feministas, que rejeitaram a ordem de prioridades proposta em nome da luta de classes; como os ecologistas radicais, que tiveram que lutar contra a assimilação da natureza a um conjunto de recursos a serem valorizados; como os camponeses, que estão fartos dos encantos do produtivismo; como os povos indígenas, que tiveram que enfrentar um julgamento unânime, que considera suas práticas como simples superstições, etc.1 (PIGNARRE e STENGERS, 2005, p. 21)

Da mesma forma, uma resistência particular por meio de redes virtuais foi reforçada nesta época. Através de plataformas, desde as mais sofisticadas até as mais básicas, artistas consagrados e iniciantes têm compartilhado com um público global todo tipo de expressões, obras e invenções. E em muitos lugares onde a internet não chega ou não funciona, a solidariedade, material e simbólica, tem inventado as formas mais simples ou lembrado as formas mais antigas de se reunir, se apoiar e compartilhar.

Para os artistas e os trabalhadores da cultura, talvez este seja também um momento apropriado para rever o que fazemos e dentro de quais formas de produção. As perguntas mais básicas sobre o que, como, e para quem tornam-se relevantes. Não se trata, como afirma Isabelle Stengers, de voltar à caverna; mas podemos nos perguntar de que maneira evoluem os modos de fazer arte que não se enquadram nas lógicas de produção do capital e do consumo. É bom, de vez em quando, retomarmos certas reflexões e ideias que nos ajudam, justamente, a avaliar percursos de criação que por uma razão ou outra ocorrem fora dos circuitos já estabelecidos e legitimados nos campos culturais e conhecidos pelas chamadas leis do mercado. Talvez, perscrutar experiências artísticas imperceptíveis, provoque novas reflexões e novos aprendizados.

Este texto não propõe, então, um estudo teórico, mas nos convida a nos determos em alguns exemplos de processos criativos que frente ao confinamento e à crise respondem com laboratórios de indagação poética, poderíamos dizer caseiros, e dentro dos quais a relação arte e cuidado, cuidado do outro, de si, do humano e do não humano, do próprio meio e da comunidade, é fundamental. Essas formas de criação, provavelmente de maneira não intencional, questionam modelos institucionalizados e nos apresentam sementes de alternativas artísticas.

$\mathrm{Na}$ Personne et le sacré ( $A$ pessoa e o sagrado), um breve e profundo texto De Simone Weil, publicado pela primeira vez na revista Table ronde em dezembro de $1950 \mathrm{com}$ o título La Personnalite humaine, le juste et l'injuste (A personalidade humana, o justo e o injusto) e retomado depois sob o novo título nos Escritos de Londres e últimas cartas

1 "ces groupes en lutte, comme les féministes, qui ont refusé l'ordre des priorités proposé au nom de la lutte des classes; comme les écologistes radicaux, qui ont du lutter contre l'assimilation de la nature à un ensemble de res-sources à valoriser; comme les paysans, qui ont assez gouté les charmes du productivisme; comme les peuples indigènes, qui ont eu affaire au jugement unanime qui identifiait leurs pratiques à de simples superstitions, etc. " (PIGNARRE, Philippe., STENGERS, Isabelle. (2005). La sorcellerie capitaliste. Pratiques de désenvoûtement. Paris: La

Découverte. 21). 
publicado por Gallimard, a filósofa francesa medita sobre aquilo, além da personalidade, que é sagrado em cada ser humano, para afirmar que "O bem é a única fonte do Sagrado" (WEIL, 2018, p. 10).2

É também dentro dessa mesma reflexão que Simone Weil entrelaça três grandes virtudes do humano: a verdade, a justiça e a beleza, tornando inseparáveis as qualidades éticas e estéticas em seu modo de conceber a vida e sua dimensão sagrada. Assim, o respeito, o ouvir os outros, o cuidado, aparecem não apenas como aptidões ou ações bondosas, mas belas. A beleza, nos diz Simone Weil, tem uma voz para chamar: "ela chama e mostra a justiça e a verdade que não têm voz" (WEIL, 2018, p. 59).

Há nos trabalhos que evocaremos agora uma forte relação entre o cuidado da vida e o gesto artístico, entre a verdade, a justiça e a beleza, tal como enunciou Simone Weil em seus profundos postulados. Neste artigo, nos detemos em quatro exemplos de mulheres criadoras que se caracterizam por uma certa leveza, ou por um claro desapego em seus modos de produzir e de se relacionar, ou como uma delas prefere dizer, de entrar em contato com o que chamamos o mundo da arte. As quatro, muito distintas entre si, poderiam ser chamadas criadoras viajantes, de longas ou pequenas viagens, ou artistas sempre em trânsito, movidas por um espírito curioso e inquieto e impelido pelo desejo de encontrar os outros, com os outros, com o mundo. 3

María Lucía Castrillón Trujillo nasceu em Medellín, onde estudou comunicação e vive em Paris há décadas. Enquanto na Colômbia Maria Lucia esteve à frente de projetos audiovisuais reconhecidos e neste país consolida seu trabalho no campo audiovisual, a França é o lugar de uma longa imersão nas linguagens do cinema, e é nesse entre dois, entre Paris e Medellín, entre Europa e América Latina onde acontece o entrelaçamento de interesses, de paixões, de temas e de formas que guiam seus trajetos criativos e que estão ao mesmo tempo vinculados às questões pedagógicas que aborda com os diferentes estudantes que ajudou a formar.

O seu mais recente filme, intitulado Carta a Inger, nos aproxima de uma das mais importantes produtoras de cinema documental do século XX, a noruega Inger Servolin, que foi, junto ao lendário Chris Marker, a fundadora da casa de produção Slon-Iskra e a impulsionadora durante toda a sua vida de importantes obras cinematográficas na França.

O filme, do qual não falaremos neste espaço e que convidamos a que descubram, evidencia, entre outras coisas, a sensibilidade compartilhada por essas duas mulheres, a cineasta colombiana e sua personagem. Ambas são amantes do cinema documentário,

2 Tradução feita pela autora deste artigo.

${ }_{3}$ Este artigo é baseado em entrevistas pessoais, realizadas pela autora deste artigo com quatro mulheres e artistas criativas, em tempos de confinamento. Entrevista com Talía Falconi (8 de agosto de 2020), entrevista com María Lucia Castrillón (15 de agosto de 2020), entrevista à Luz Estela Gutiérrez (17 de outubro de 2020), entrevista com Valentina Hincapié Martínez (22 de outubro de 2020). 
ambas conhecedoras do poder das imagens nas lutas políticas de pessoas e coletivos, ambas discretas para nomear suas próprias conquistas e dificuldades em um campo, como tantos outros, onde os homens ocuparam o primeiro plano.

Para a realização desse belo longa-metragem, que não contou com a segurança proporcionada pelo apoio institucional ou o financiamento de uma ou mais produtoras, ou pelo menos o acompanhamento de uma equipe mínima, Maria Lucia apela ao seu grande desejo de contar a história de Inger e ao vínculo afetivo que a une a ela. Desejo e afeto são as fontes da imensa energia necessária para um trabalho artístico que levará anos para ser realizado. Indiscutivelmente, uma experiência como essa nos permite confrontar as lógicas conhecidas e profundamente incorporadas das formas de produção cinematográfica e artística.

"Foi como começar a dizer: renuncio à pretensão técnico-estética e vamos ver como vai saindo, mas é uma aposta em que há um grande risco e poucos interlocutores que possam realmente me dar apoio.", diz Maria Lucia sobre o momento em que ela decide se aventurar a fazer o filme. Como uma mestra artesã, María Lucía dedica-se com paciência à escrita do roteiro, à filmagem, à edição e até ao posterior processo de divulgação do seu filme. E é, sempre em seu apartamento na Rue De La Reunion em Paris, e nas longas conversas com Paul Perez, seu parceiro na época, que ela encontra o ponto de vista externo que lhe permite seguir em frente sem se perder em suas próprias dúvidas sobre o rumo que o filme estava tomando.

\begin{abstract}
Acho que não teria feito o filme que fiz sem o apoio do Paul. Ele ouviu meu discurso, meu monólogo, me viu trancada, desiludida, animada, triste. Passa-se por toda essa montanha de sentimentos e, além disso, enquanto uma ideia amadurece e uma ou outra decisão é tomada e enquanto se está ao mesmo tempo trabalhando para ganhar a vida, se passam meses. Então há momentos em que é muito importante ter com quem desabafar, ter um interlocutor que nos faça perguntas, perceber a própria contradição, o próprio vazio ou a própria certeza perante uma coisa ou outra. (CASTRILLÓN, 2020)
\end{abstract}

Nesse processo artístico, a motivação inicial, as dinâmicas nas quais se enquadra, bem como a forma de produção que o próprio trabalho gera, dependem, em boa medida, do contato afetivo, de conexões de amizade vitais.

Agora uma nova criação documental ocupa Maria Lúcia e mais uma vez a coesão entre verdade, justiça e beleza enunciada por Weil se revela em seu desenvolvimento. Em fevereiro de 2020, Maria Lucia, preocupada com a frágil saúde de uma de suas amigas mais próximas, a compositora, produtora de música infantil e pedagoga Tita Maya, com diagnosticada com câncer, decide deixar Paris para visitá-la em Medellín. Tita morre alguns dias após a chegada de Maria Lúcia e ela permanece sozinha no apartamento de sua amiga durante todos os meses do confinamento decretado por causa da pandemia.

Essa experiência que tive de chegar e assistir e continuar a fazer parte desse momento tão sagrado e particular, essa experiência 
tão forte e intensa e do exemplo da Tita e da sua forma de assumir aquele momento, que foi de uma grandeza, de uma inteligência e uma força impressionante, ela me faz sentir grata a ela. Ela me ensinou muitas coisas, mas principalmente com a morte me deu uma lição de vida que vai além do discurso, seja filosófico, espiritual, tranquilizador. Assistindo a tudo isso, sinto que há algo que passou pelo meu corpo; quando digo que passou pelo meu corpo, é que existe um entendimento que não é só racional, teórico, espiritual, não! há outra casca, difícil de nomear, de definir, mas concreta. (CASTRILLÓN, 2020)

Sentimentos e pensamentos dentro dessa experiência limite se tornam o ímpeto de um novo filme. Estar ali, junto com alguém querido, testemunhando e acompanhando seus últimos dias, guardando o silêncio de um testemunho amoroso; compreender a força, a dignidade e de certa forma a beleza que envolve aquela experiência final, como uma aura sutil mas real, já faz parte, ou de alguma forma estabelece o processo que se torna uma ideia cinematográfica, dessa vez sobre Tita. Um documentário sobre a coerência de Tita, a partir de sua casa, em relação às suas obras, sobre suas formas de sentir, pensar e fazer e de se relacionar consigo mesma, com o seu meio, com os seres vivos, humanos e não humanos.

O filme foi-se imaginando a partir de três fios narrativos, ou pode-se dizer três dimensões intimamente relacionadas entre si: conversas com Lulu, a filha de Tita, as muitas e pequenos cadernos nos quais Tita registrava e criava, e a permanência de Maria Lucia na casa de Tita que possibilita o contato contínuo, silencioso, com seus objetos e espaços.

A Tita tinha uns cadernos aos quais não colocava data, sempre tinha um no bolso e os outros ia guardando, cadernos de uma vida toda, são 40 caderninhos por aí. Muitos ilustrados com $O$ Pequeno príncipe... neles ela escreve o projecto que vai fazer ou que está fazendo, e com esses cadernos a essência de seu pensamento começa a ser revelada Muitas vezes esses caderninhos são o resumo de um curso que ela fez ou que ela deu, ou de uma viagem que ela fez ou de um projeto; ou se há alguns endereços são contatos relacionados ao momento, ou com a ideia que tem em mente e aí há uma definição muito pedagógico-filosófica da coisa, da forma como o seu sonho vai se concretizar, a estratégia financeira que vai concretizá-lo e acaba colocando até os nomes daqueles envolvidos no trabalho, $O$ fato é que as relações do que esses caderninhos contêm com certos objetos da casa ficaram evidentes para mim, como um pequeno relógio de cristal para acompanhar a situação, o pequeno príncipe, com a ovelha no terrário na varanda com cactos e o lagarto, símbolo de La tierra es la casa de todos, projeto que ela idealizou há mais de 30 anos; ou seja, a casa começa a falar comigo, a revelar-me as suas convicções mais íntimas e consigo compreender melhor o seu pensamento e medir a sua coerência. (CASTRILLÓN, 2020) 


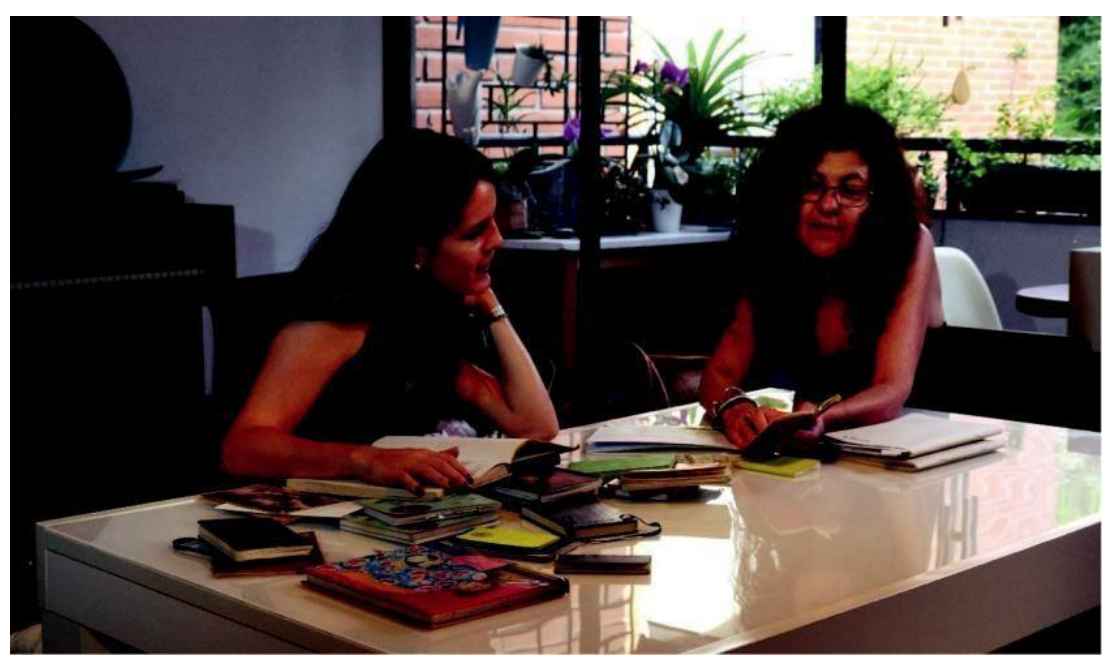

Figura 1 - Arquivo Pessoal María Lucia Castrillón Trujillo, 2020.

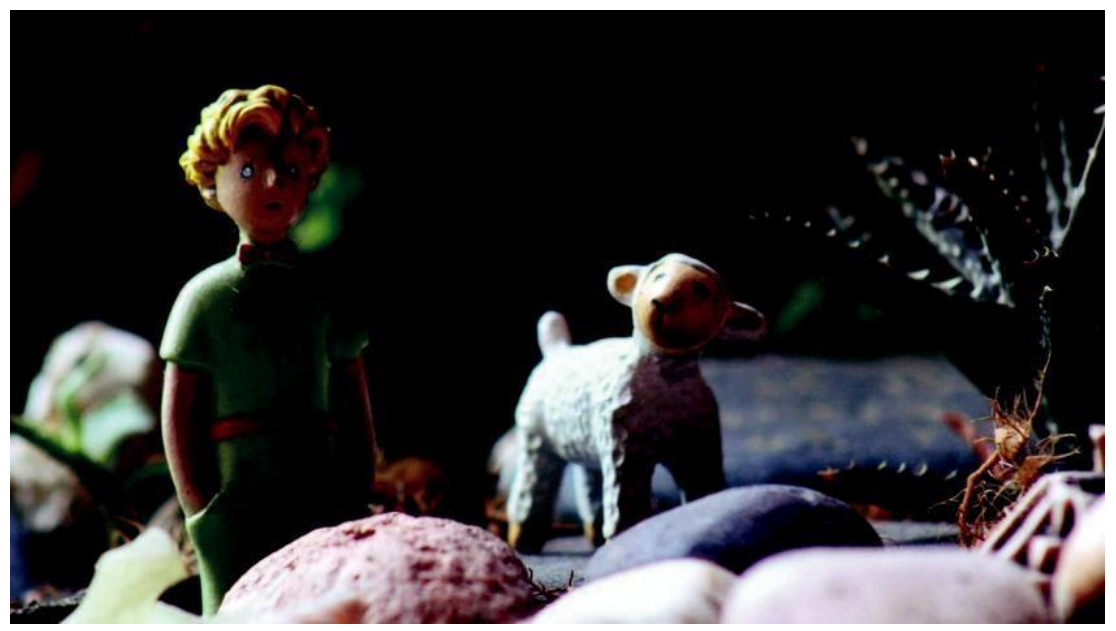

Figura 2 - Arquivo Pessoal María Lucia Castrillón Trujillo, 2020.

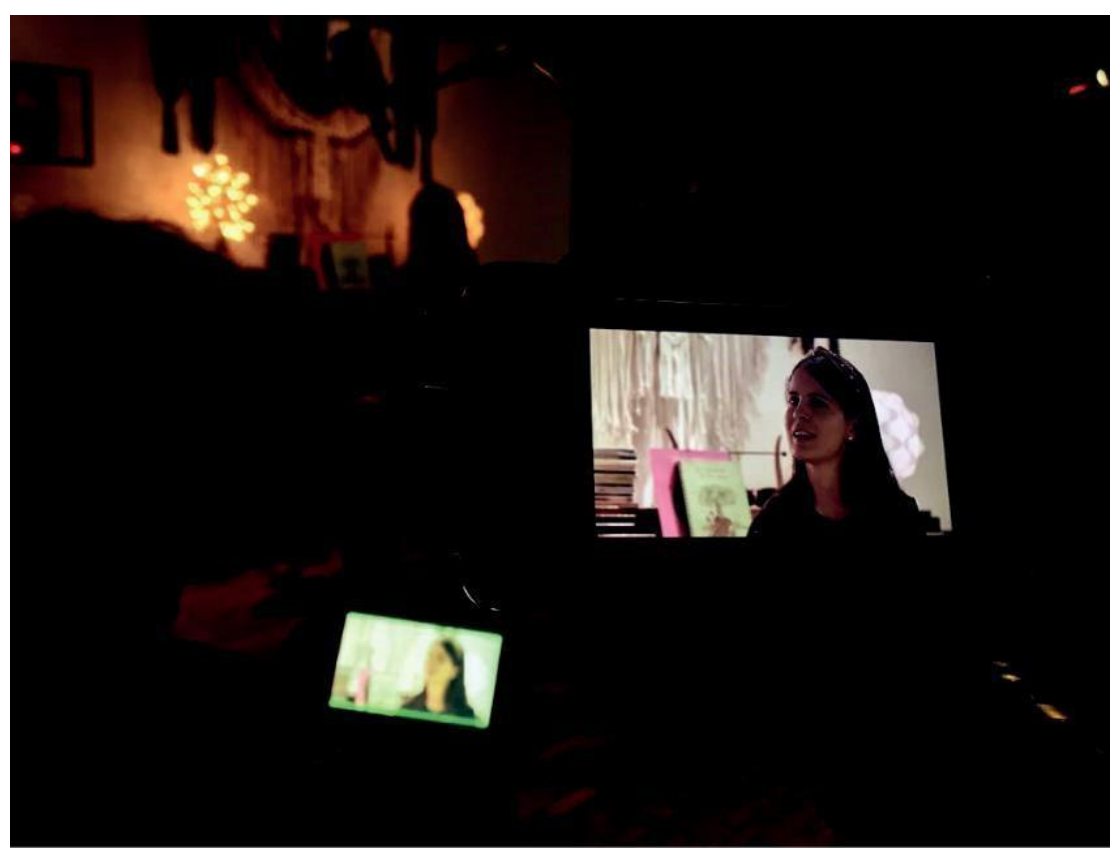

Figura 3 - Arquivo Pessoal María Lucia Castrillón Trujillo, 2020. 
Muito provavelmente, o filme será atravessado por experiências particulares de tempo. O tempo de uma vida rica, a de Tita, o dos objetos através dos quais emerge poeticamente sua memória e o tempo em que Maria Lucia, com Lulu e Gabriel, o pai de Lulu, cineasta também, coescrevem a história empolgados pelo cuidado amoroso da memória de Tita. Além disso, o tempo será necessário para amadurecer as ideias e materializá-las no filme. A singularidade desta nova produção, também baseada nos afetos, e por razões distintas de Car-ta a Inger, igualmente livre das pressões que impõe a indústria, torna-se celebração da duração, aquela que permite a atenção nos detalhes. Um tempo mais dilatado e tranquilo no qual emerge a verdade e a bondade da vida possibilitando na obra artística a potência do íntimo.

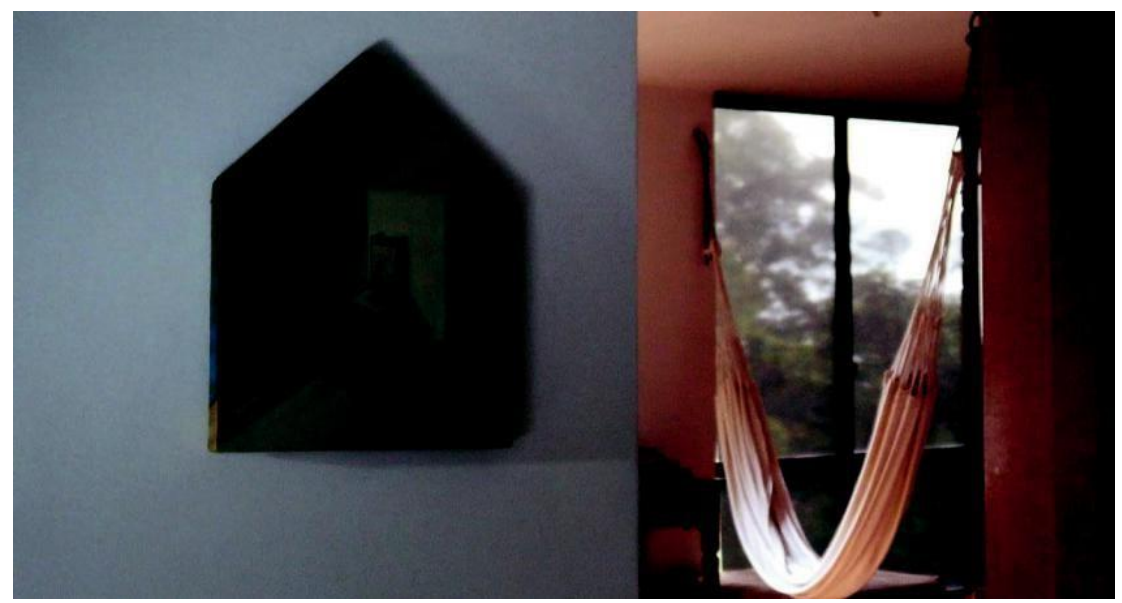

Figura 4 - Arquivo Pessoal María Lucia Castrillón Trujillo, 2020.

Mais ao sul, na cidade de Quito, a coreógrafa e dançarina equatoriana Talía Falconi vive esta época do confinamento num pequeno apartamento que herdou de seu pai. Talía sempre foi uma artista nômade e foi quase um acaso viver os longos meses de confinamento no seu espaço em sua cidade natal. Embora a formação de Talía como dançarina de dança contemporânea comece no Equador, em estreita colaboração com os artistas que formaram a chamada Frente de Danza Independiente, ela viajou desde muito jovem e, em Nova York, foi certificada na escola Martha Graham antes de continuar estudando e criando na França. Talia também morou na Venezuela e no México e apresentou suas obras em muitos lugares do mundo, concentrando-se por décadas em um trabalho que de alguma forma vai além da dança para se aprofundar em questões sobre as formas poéticas do movimento.

O movimento e suas possibilidades é seu tema obsessivo, ele abarca sua própria condição existencial. Ela vai mudando de país, de contexto, de casa, de trabalho e concentra-se numa observação constante e penetrante dos gestos, mesmo os menores do cotidiano, antes de serem transformados ou perdidos nas suas coreografias.

A vida de viajante, de desenraizamentos sofridos e liberdades celebradas, levou Talia a reconhecer profundamente seu próprio corpo como seu principal e mais ínti- 
mo espaço: "o lugar do fim é um e no meu caso é o meu corpo", esclarece Talía. É assim que a constante descoberta das possibilidades do corpo e o autocuidado como método tornam-se condições necessárias do processo de criação. E quanto ao corpo confinado por meses aos espaços da própria casa? Essa parece ser a pergunta que permeia a sua mais recente coreografia: um somatório de pequenos ensaios de dança onde a vemos como a maçã do poema infantil caminhando da mesa para a sala de jantar, e no caso dela também para o banheiro, o quintal, a cozinha, o armário, a cama, o jardim, a poltrona...

Todos os dias, desde o final de março, eu acho, uma semana estando aqui, eu comecei a fazer esses exercícios, breves improvisações. Eu colocava a câmera do tablet, apoiando em qualquer parapeito até encontrar ângulos que me interessavam para gravar. Via o enquadramento, o espaço do enquadramento e era esse espaço que provocava o movimento. Eu fiz isso praticamente todos os dias, uma ou duas vezes até meados de junho. " "(...) As improvisações foram e se tornaram simplesmente uma necessidade cotidiana, de fazer aquele exercício cotidiano, um contato com os objetos. Testo o que há no espaço, que apoios, que mobilidades posso conseguir, que limites físicos tenho; isso do espaço pequeno reduzido, que possibilidades físicas ele me oferece e me jogo na improvisação. (FALCONI, 2020)

Talia encontra no jogo corporal uma maneira de transformar os limites físicos em possibilidades criativas de habitar. Uma ideia nova para uma mulher nómade que de repente se encontra confinada. A qualidade do movimento como pergunta e as explorações realizadas a partir dessa estética do confinamento tornam-se uma rotina diária de cuidar de si e das coisas que compõem sua casa. A relação com os objetos cotidianos deixa de ser conhecida, mecânica ou apenas utilitária, para se transformar em material de criação.

É preciso medir também a intensidade do movimento que se explora, ou seja, por exemplo, agora que estou sentada neste sofá, acho que em algum momento fiz alguma improvisação aqui. Esse sofá é muito frágil, a perna pode quebrar, então eu tenho cuidado, assim como também tenho cuidado nos espaços onde há pequenas coisas frágeis. Eu não fazia catarse com o movimento para me jogar onde tudo pode se quebrar. Quanta força e que intenção você pode colocar no movimento? Existem pontos no espaço obviamente como as paredes, apoios fixos, fortes, resistentes nos quais justamente você pode apoiar todo o peso do corpo para se empurrar e para que isso lhe dê o impulso para o outro movimento, mas há outros lugares que demandam um impulso interno, porque o apoio externo é fraco. Assim você se apoia no impulso de uma pequena parte da caixa torácica e esse movimento da caixa torácica pode se estender até os dedos; isso vai tendo um senso de movimento e cria sua própria dramaturgia a partir daí. Estar atento também ao espaço do enquadramento da câmera também dá como disse um limite de movimento ou a possibilidade de desaparecer e aparecer naquele enquadramento ou de utilizar partes do seu corpo e de uma relação focada por vezes no movimento afetivo, no contato com o próprio quarto ou com a própria cama. (FALCONI, 2020) 
Desses exercícios diários diante de uma câmera não profissional, resulta uma série de variações que Talía intitulou Fluctuante. Nessas variações em torno dos espaços da casa, à materialidade das coisas e do próprio corpo em movimento, revela-se uma grande força expressiva. O movimento faz um gesto artístico, uma dança leve de horas e dias; repetição imperfeita que mostra que, na realidade, cada momento da vida é novo, embora ainda contenha as milhares de camadas de experiência que o constituem.

É impressionante que um estudo aparentemente simples, feito em casa, sem grandes recursos, mas no qual o corpo se desenrola poeticamente, nos transporte assim para as possibilidades sensuais do espaço. A dança nos permite uma meditação profunda sobre as coisas, sobre o tempo e os ritmos da vida cotidiana.

\begin{abstract}
Todas essas coisas vinham do afeto pelo espaço. Por exemplo, quando estou no quintal, costumava contar sobre a forte relação afetiva que tenho com as plantas; Isso afeta a maneira como você se aproxima de uma planta para observá-la, para vê-la com um certo cuidado e uma certa delicadeza. Também me lembrei da minha amiga Lilian que trabalha com fantoches e objetos e falou "sobre a alma das coisas"; as coisas têm sido uma parte importante desse confinamento e têm sido uma companhia. Sim, todas as coisas têm sido como minhas companheiras nesse tempo, assim como os espaços físicos ao meu redor. (FALCONI, 2020)
\end{abstract}

Nos últimos anos, Talia esteve ligada à Universidad de las Artes em Guayaquil como professora de dança contemporânea. A cidade foi uma das primeiras na América Latina a sofrer as duras consequências da pandemia. De sua casa em Quito, ela, como tantos professores em tantos lugares do mundo, continuou a dar seus cursos pela internet apesar das dificuldades materiais e emocionais que viviam os estudantes. A maioria vem de regiões muito simples e possuem baixos recursos econômicos. Experimentar com a dança em seu apartamento Ihe esclareceu sobre possíveis rotas de trabalho em suas aulas. Mais uma vez, seu próprio corpo foi o laboratório de indagações que provocam perguntas transmissíveis. Em seguida, convidamos você, através do link, a conhecer Fluctuante, o trabalho que resulta dessas improvisações e que foi musicalizado pelo músico argentino Federico Valdés: https://vimeo.com/407826146 (senha: fluctuante).

O cuidado também está no centro da vida e das reflexões de Luz Stella Gutiérrez Henao, uma artista autodidata. Luz Stella nasceu no seio de uma família numerosa em um bairro movimentado de Medellín no final dos anos cinquenta. Ele trabalhou em tarefas distintas e viajou muito por anos. Seu interesse pelo mundo da arte a levou primeiro à fotografia e depois a uma exploração mais ampla, onde os materiais e as formas dependem cada vez mais das ideias e temas que a ocupam. Da mesma forma, Luz Estela aproximouse de pensamentos, disciplinas ou discursos por épocas e de acordo com o que desperta sua curiosidade em um determinado momento. Desse modo, a psicanálise, alguns textos filosóficos, históricos ou literários têm sido para ela temas de meditação.

Cada lugar em que Luz Stella viveu, um sótão em Paris, uma pequena a casa numa 
colina popular de Medellín ou o apartamento em que passou os últimos anos e que é ao mesmo tempo sua casa e oficina, sempre teve uma decoração delicada. A austeridade, a beleza e o gozo do tempo contam no seu mundo e isso se materializa em suas coisas, seus espaços e seus gestos vitais: cozinhar, caminhar, acolher viajantes de muitas origens, porque no seu caso a hospitalidade é uma constante. Pode-se dizer que as ideias de uma moral pós-cristã, para a qual a solidariedade é uma prática importante, e um hedonismo do ser e não do ter, defendidas pelo filósofo Michel Onfray, foram discretamente encarnadas por Luz Stella sem ter que defendê-las explicitamente.

Ou melhor, a vida dessa mulher, pouco inclinada ao consumo, atenta ao seu meio e ao dos outros e à espreita dos seus próprios desejos e dos seus particulares caminhos criativos, parece responder, à sua gentil maneira, e pelo menos de forma individual, ao chamado de Guattari nas suas Três Ecologias:

Tornou-se igualmente imperativo confrontar seus efeitos [do poder capitalista] no domínio da ecologia mental no seio da vida cotidiana individual, doméstica, conjugal, de vizinhança, de criação e de ética pessoal. Longe de buscar um consenso embrutecedor e infantilizante, no futuro se procurará cultivar 0 dissenso e a produção singular de existência. (GUATTARI, 2003, p. 36)

Em suas andanças por Medellín, e por outras cidades cada vez que sua instável economia o permite, e em seus lentos projetos artísticos, Luz se dispõe a esse desdobramento de subjetividade singular afirmada pelo pensador francês. Um par de anos atrás, ela decidiu expor em sua própria casa e para alguns amigos, que mais tarde convidaram outros amigos, uma peça intitulada "Alfabeto para escribir y dibujar en la máquina de coser". A ideia desse trabalho está ligada, como várias de suas explorações, ao mundo da infância; às suas lembranças dos primeiros exercícios de caligrafia e à lembrança de sua mãe sentada trabalhando com a máquina de costura.

Eu acho que eu queria fazer algumas passagens entre duas maneiras de escrever; o bordado em tecido e escrever no papel aprendendo nomes, aprendendo os nomes dos animais. Relembrando o momento em que aprendi a escrever, recortar, colar, nomear, esboçar uma figura, lembrei que minha mãe também fazia isso com os vestidos que fazia para nós quando éramos pequenas. Ela fazia o mesmo que eu, mas com a máquina, a máquina era como o dispositivo, a ferramenta que lhe permitia fazer bordados e paisagens ou flores. Nos vestidos ela fazia aplicações, depois cortava, colava, às vezes também bordava as meias, os aventais de escola. (GUTIÉRREZ, 2020) 


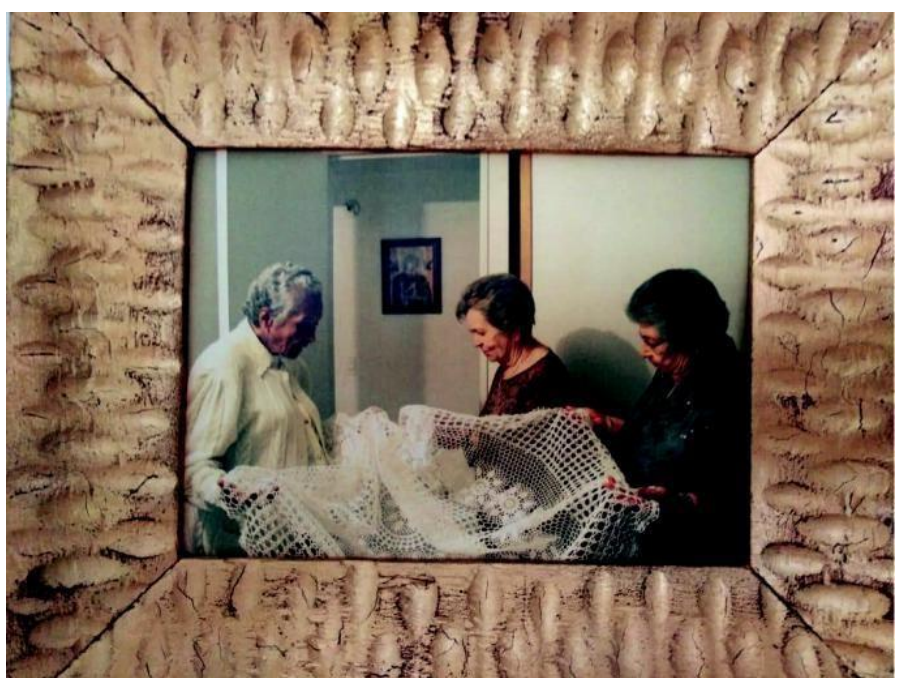

Figura 5 - Arquivo Pessoal Luz Stella Gutierrez, 2018.

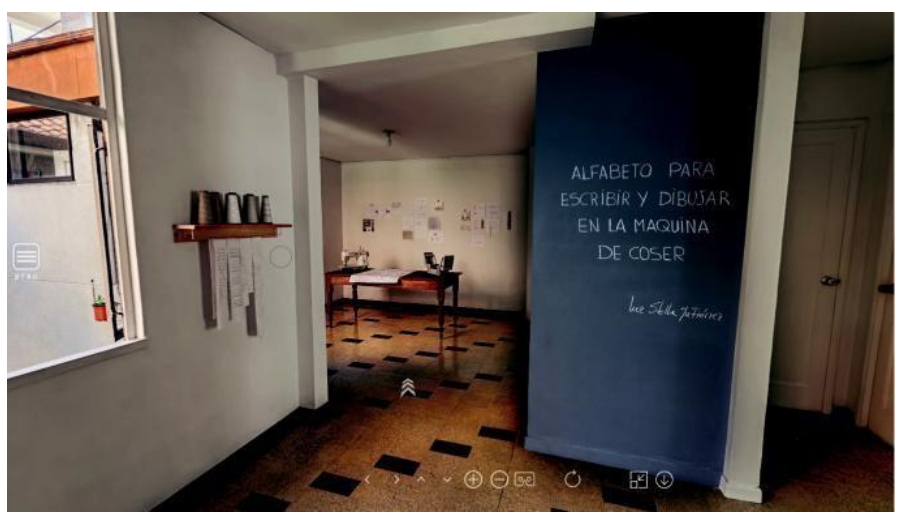

Figura 6 - Arquivo pessoal Luz Stella Gutierrez, 2018.

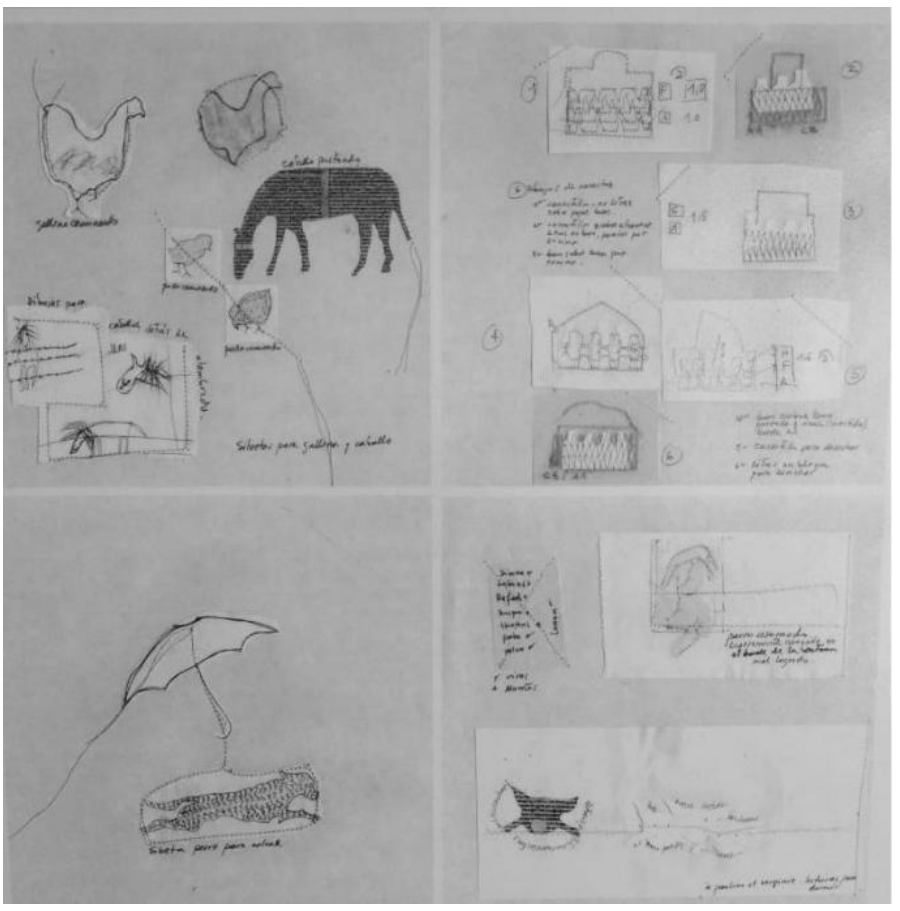

Figura 7 - Arquivo Pessoal Luz Stella Gutierrez, 2018. 
A atenção que uma menina concentra em sua mãe, em suas longas jornadas de trabalho e naquela máquina que para ela também nomeava e escrevia o mundo, emerge com uma particular sensibilidade no trabalho de Luz Stella. Na exposição, os materiais, todos frágeis: papel, fios, tambores de papelão, uma velha máquina de costura, convidam a um contato cuidadoso, com eles, e também com o que eles simbolizam: as memórias das vidas de tantas famílias comuns, seus ritos vitais, sua sobrevivência, as lembranças agora turvas, tristes ou brilhantes da infância.

\begin{abstract}
Identifiquei que esta máquina tinha alguns pontos para bordar e pensei que esses pontos eram como as consoantes de um alfabeto, e aí lembrei que quando eu era pequena se fazia recortes de palavras do jornal e formava frases, era um exercício na escola. Retomei isso e fiz as cinco vogais no papel do jornal, foi a transição para o exercício da escrita, da caligrafia. Construí um alfabeto entre consoantes e vogais. Então também me lembrei que quando eu estava aprendendo a escrever era sempre a palavra cachorro e o recorte do cachorro. Assim cheguei aos "animais da infância", que também eram animais que estavam na casa também ou com os que eu tinha contato, mas que não tinham nada a ver com aqueles que eu aprendia a recortar. Essa primeira peça se chamou "Alfabeto", era composta pelos pontos à máquina que eram as consoantes e pelas vogais que eram os recortes de jornal.
\end{abstract}

Outra peça foi chamada de "Vocabulario" a partir de uma associação dos dispositivos da máquina com os da escrita, por exemplo, o figurino é a cartilha da escrita; o carimbo na máquina, que é o guia, é a linha na página do caderno; o disjuntor, que é o objeto usado para interromper o que se fez de errado na costura, é a borracha. Então, assim, cheguei a uma série de substantivos que tinham uma correspondência na ação com um dispositivo e depois outra que se chamava "El renglón", uma alusão ao que marca o limite, eu fiz uma associação com os padrões de costura que as mães tinham nas casas quando costuravam, que cortavam e era o padrão que repetiam. Na linha se mede para não sair, porque um dos objetivos da caligrafia da infância é não sair da linha, não sair, colorir corretamente, enfim, todo esse tipo de coisas. (GUTIÉRREZ, 2020)

A aproximação a este trabalho que evoca a infância e as múltiplas escrituras que não só ensinam a nomear o mundo, mas que escrevem sobre nós, nos moldam ou nos configuram, abre a reflexão sobre como passou para ela o ano da pandemia.

Luz se reveza com duas de suas irmãs para cuidar da mãe, hoje com 93 anos. 0 tempo é organizado em torno dessa tarefa. Ela faz o trajeto entre sua casa no bairro Laureles e a casa de sua mãe em Calasanz caminhando, e então lá há uma série de rotinas que ela transforma em pequenos rituais de acompanhamento. No caminho para a casa da mãe, ela para junto a algumas árvores do bairro, árvores que conhece e que suscitam todos os tipos de perguntas, árvores que são o tema central do seu novo trabalho criativo. Ela se concentra na observação detalhada de suas mudanças, de seu tamanho, de suas cores e de suas texturas, na vida que nelas passa. E então na casa de sua mãe cuida da vida dessa mulher já 
idosa, de sua pele delicada, de seus movimentos simples e difíceis, de idéias que às vezes expressa sobre seu apego à vida e medo da morte. Luz Stella tira fotos das árvores e também fotos de sua mãe, de instantes anódinos mas carregados da verdade e da beleza trágica do efêmero.

De volta a sua própria casa, as ideias sobre as árvores, amigos silenciosos no meio de uns percursos que se tornaram tensos por conta da pandemia e a desconfiança que ela gera entre os transeuntes, e as ideias sobre esse tempo pausado da vida de sua mãe, vão se cruzando para dar lugar ao novo trabalho que por agora se organiza em três momentos possíveis: o quintal, o bairro, o jardim botânico.

No primeiro eu quero mostrar um lugar onde há uma taxonomia, formas, pequenas e médias, contidas em recipientes de fácil acesso e que têm funções medicinais, alimentícias, culinárias, ornamentais; trata-se de contar esse universo e as coisas que acontecem a essas plantas. Porque elas pegam pragas, algumas precisam de sol, outras não. Tenho interesse em recriar um lugar articulado pelas palavras, um lugar onde existem geometrias, formas, funções, etc., esse seria o quintal.

O outro espaço que digo é o terreno ou o bairro, seriam árvores que estariam mais articuladas pelos cinco sentidos, sim muito sensorial. Pensei na mangueira, na laranjeira, nos pomos e no goiabeira, que são árvores que estão na esfera do bairro, que na infancia passaram mais pelo tocar, pelo comer, pelo escalar, pelas brincadeiras, e onde os sentidos estão completamente abertos porque nós comemos seus frutos, escalamos, fizemos balanço, brincamos, cheiramos. As mangas estavam sempre à vista no bairro.

O terceiro seria um convite para uma viagem ao interior da árvore, embora sejam muito bonitas e não seja preciso saber o que fazem, nem como fazem, gostaria de representar todas aquelas perguntas que surgem em mim quando ando e as observo e vejo redes de comunicação completas em seus processos, rodovias pelas quais circula a seiva em seus caules e vejo seus tipos de pele... Fico me perguntando como evocar esse mundo inteiro. (GUTIÉRREZ, 2020)

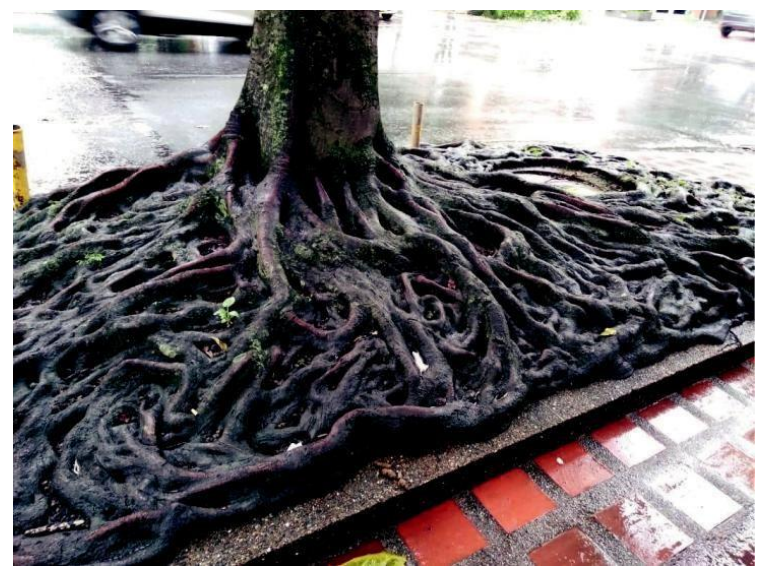

Figura 8 - Arquivo pessoal Luz Stella Gutierrez, 2018. 
Para concluir este breve artigo, é oportuno e sobretudo francamente inspirador analisarmos um pouco essa afirmação que encontramos em um dos capítulos da tese de graduação de Valentina Hincapié Martínez, jovem recém-formada do Instituto de Filosofía da Universidad de Antioquia: "Pelos alcances e magnitudes da rede heterogênea de dispositivos que mediam economicamente a vida, é difícil mas possível agenciar modos de vida distantes e dissidentes das mediações econômicas próprias do biopoder; e uma dessas emergências é o contato com a terra através de seu cuidado e a sua defesa."(HINCAPIÉ, 2020, p. 25)

Valentina, que mora no campo, questiona em seu trabalho os modos de vida e a resistência de uma comunidade camponesa da aldeia Palmirita do leste de Antioquia. Os habitantes desaa região foram vítimas do longo conflito armado da Colômbia e há alguns anos se organizaram para resistir a outras violências, entre as quais estão aquelas dos projetos econômicos de grandes empresas extrativistas que pretendem privá-los de água e, portanto, de suas próprias formas de existência.

A jovem filósofa se interessa pelo pensamento de Giorgio Agamben e especialmente por alguns conceitos fundamentais como a vida nua, dispositivo, máquina antropocêntrica e profanação, e os conecta com as práticas concretas dos camponeses de Palmirita e com sua luta política, diária e criativa para defender a água, as colheitas agrícolas, os animais do lugar e em suma toda a vida que não pode ser separada de sua forma e que Agamben chama de forma-de-vida.

Cruzando suas reflexões filosóficas com uma relação horizontal, afetuosa e constante com os moradores da aldeia Palmirita, Valentina propõe:

\begin{abstract}
pensar sobre esse problema apelando para formas-de-vida que pela indissociabilidade de sua forma são politicamente potentes e dão lugar a uma forma específica de se tornar comunidade da qual emergem redes de cuidado entre viventes cualsea/quolibet que se opõem radicalmente ao cenário tanatopolítico que a biopolítica proporciona. (HINCAPIÉ, 2020, p.28)
\end{abstract}

Este não é o espaço para analisar a abrangência da obra filosófica de Valentina ou aa abrangência política dos processos comunitários dos camponeses de Palmirita, mas uma experiência como essa, também mediada por práticas artísticas na comunidade, nos permite fazer referência a essas outras formas da arte do cuidado e da relação entre arte e cuidado que estão no centro dos diferentes processos aqui mencionados. Valentina e as e os camponeses de Palmirita teceram juntos um mural que se tornou um manifesto de seus pensamentos e desejos de autoproteção e de proteção do morro el Chaquiro, onde nasce a água de todos. Da mesma forma, juntaram-se ao trabalho os companheiros de Valentina, que encontraram no teatro uma possibilidade de expressão lúdica da memória, dolorosa mas também esperançosa da comunidade. 


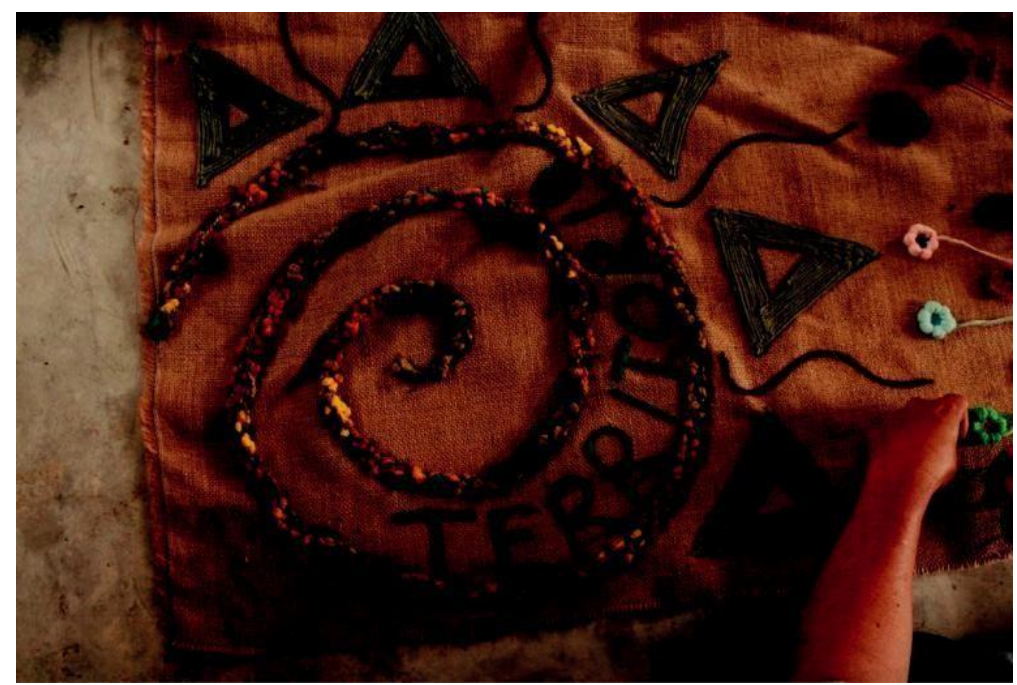

Figura 9 - Arquivo Pessoal Valentina Hincapié, 2019.

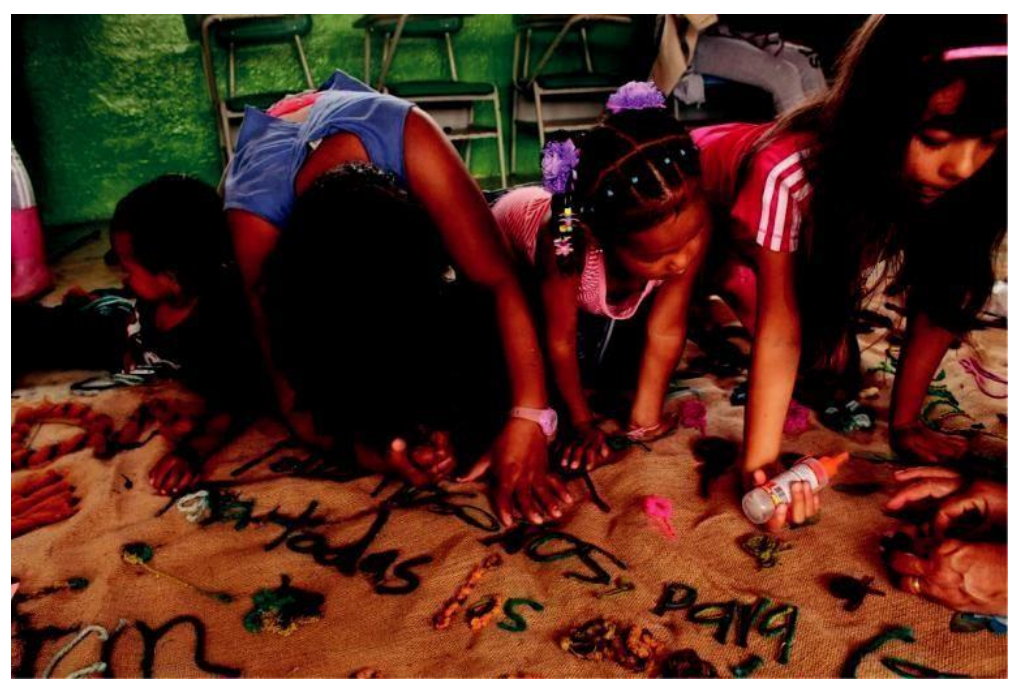

Figura 10 - Arquivo Pessoal Valentina Hincapié, 2019.

Reconstruindo em nossas conversas o entrelaçamento entre práticas no terreno e pensamento filosófico, Valentina evoca o tempo em que esse interesse foi despertado. Durante boa parte de seus estudos, a teoria crítica e a Escola de Frankfurt atraíram sua atenção, mas em algum momento de sua carreira ela se aproximou de um grupo de dança contemporânea e a dança revelou a distância que naquele momento sentia com seu próprio corpo. Depois de uma fase, diríamos de certa catarse, esse reencontro com o corpo sensível foi modificando também seus interesses filosóficos. A possibilidade de entrar em uma filosofia igualmente rigorosa, mas mais próxima e orgânica, mais vitalista, no sentido de Spinoza, diz Valentina, aparece para ela no pensamento de Giorgio Agamben. A dança marca o momento de uma reviravolta, uma mudança filosófica e uma mudança de rumo para um trabalho no qual os conceitos não se separam da vida cotidiana. No trabalho de campo realizado, como já dissemos, na aldeia Palmirita, são colocados em relação e em tensão os conceitos de Agamben, as próprias perguntas e os processos de cuidado criativo e de reivindicação das formas de vida camponesa da comunidade. 
Para uma das primeiras oficinas que aconteceram na aldeia, Valentina recebe os conselhos de Lucas Muñoz, um artista do leste de Antioquia. A partir de um trabalho de experimentação com folhas e resinas que ela chama de "Una cartografía de texturas" surgiram memórias cotidianas, fragmentadas, imprecisas, parte da vida e das tradições das e dos camponeses, não só de agora, ou não tanto, lembranças do conflito ou dos sofrimentos durante a guerra, mas das colheitas, dos saberes sobre as plantas, dos nomes de árvores e flores, e sobretudo e além disso, apesar da dificuldade do grupo para abordar racionalmente esse gesto, com este foi criada uma ponte para uma rica relação de participação e compromisso com aquela segunda parte da obra que chamaram de "Tejiendo el Chaquiro".

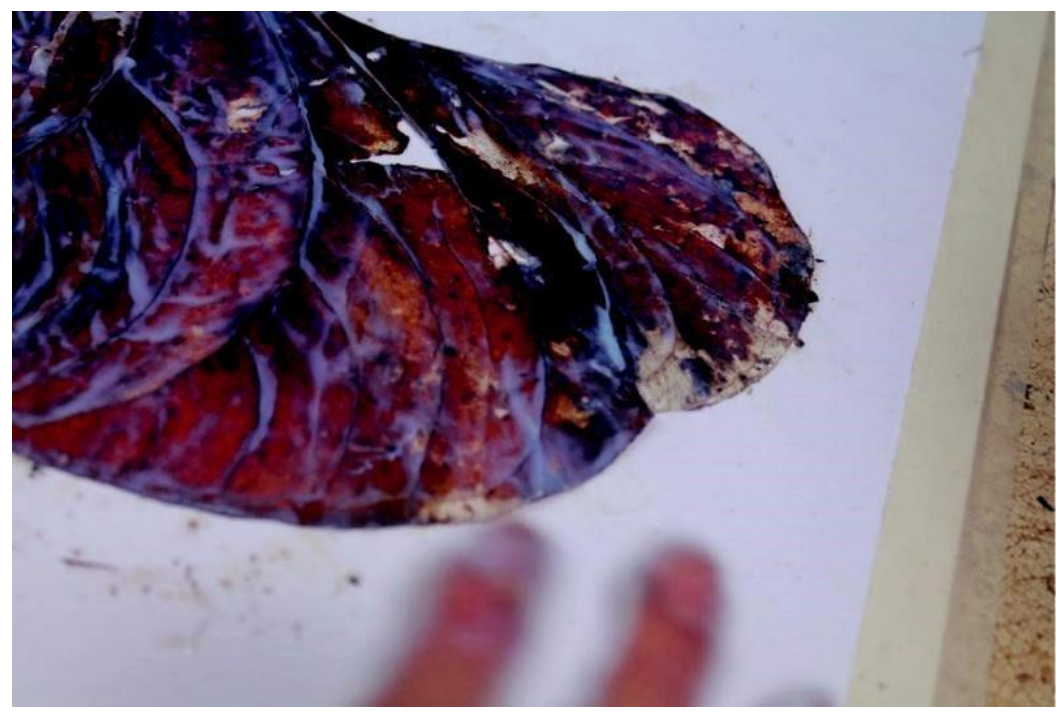

Figura 11 - Arquivo Pessoal Valentina Hincapié, 2019.

Alguns camponeses de Palmirita não leem nem escrevem, mas, em vez disso, se dispuseram com muito entusiasmo a participar na elaboração do mural tecido. Os mais novos escreviam, as e os outros bordavam e completavam e, sobretudo, diziam durante as conversas as frases que queriam e em que cores. Com o trabalho experimental da cartografia de texturas e com essa escrita tecida, Valentina consegue se afastar do domínio do logos para abrir a entrada às expressões próprias da comunidade, às suas vozes e modos de autorrelato. "Tejiendo el Chaquiro" representa uma escritura camponesa sobre o cuidado em sua maior extensão: o cuidado da vida como um todo.

Portanto, encerramos com esta citação de Valentina que nomeia claramente este e os demais processos criativos que quisemos evocar aqui:

"afirmamos que quando os homens, como é o caso dos camponeses e camponesas de Palmirita, vivem vidas movidas pelo contato com a terra desde sua defesa e cuidado, não só alimentam as possibilidades reais de uma profanação dos dispositivos da máquina antropológica, mas também estabelecem um horizonte de possibilidades para a própria terra: para o morro, para o rio, para seus animais, para as montanhas. Assim, é estabelecida uma ampla rede de cuidado a todos os viventes/quodlibet que constrói um cenário não exclusivamente antropológico, mas baseado em relações orgânicas com a vida."(HINCAPIÉ, 2020, p. 33) 


\section{Referências}

GUATTARI, Félix. Las Tres Ecologías. Valencia: Pre-textos. 2003. 80p.

HINCAPIÉ, Valentina. Comunidades en devenir: forma-de-vida y ética del víncu-lo ontológico contingente (Tesis de pregrado Filosofía), Universidad de Antioquia, Colombia. 2020.

PIGNARRE, Philippe; STENGERS, Isabelle. La sorcellerie capitaliste. Pratiques de désenvoûtement. Paris : La Découverte. 2005. 238p.

WEIL, Simone. La personne et le sacré. Paris: Éditions Allia. 2018. 80p. 